\title{
Escuta aos estudantes: Principio pedagógico na educação de jovens e adultos
}

\author{
Escucha a los estudiantes: Principio pedagógico en la educación de \\ jóvenes y adultos
}

Listening to students: pedagogical principle in youth and adult education

\author{
Cristiane Rodrigues Madeira ${ }^{1}$ \\ Everton Fêrrêr de Oliveira ${ }^{2}$
}

\begin{abstract}
Resumo
O presente trabalho tem como objetivo investigar os motivos sobre o retorno dos sujeitos não alfabetizados para as salas de Educação de Jovens e Adultos, bem como aquilo que pensam, e esperam ao estarem nesta modalidade de ensino. Para tanto realizei uma pesquisa na escola EMEF - Escola Municipal de Ensino Fundamental (Escola Pública Municipal) da cidade de Jaguarão - RS a fim de conhecer esses indivíduos e assim compreender, as causas que eles apontam para a volta a escola, depois da ausência de muitos anos do estudo. Como forma de reunir dados acerca da temática, lancei uso de um roteiro de entrevista semiestruturada e roda de conversa com os estudantes. Quanto à fundamentação teórica tratei de reunir estudos sobre o ensino e aprendizagem, seus modelos pedagógicos, suas concepções epistemológicas ligadas a Alfabetização e Educação de Jovens e Adultos. A iniciativa não possui dimensões grandes, mas espero auxiliar em minimizar a dúvida que move meu trabalho, e assim trazer alguma contribuição para outros educadores e educandos sobre a necessidade de conhecimento, acerca das motivações deste público trabalhador, que vence anos de preconceito e dependência de outras pessoas, no mundo letrado em que vivemos.
\end{abstract}

Palavras-chave: EJA; alfabetização; motivos.

\section{Resumen}

Este estudio tiene como objetivo investigar las razones para el retorno de personas no alfabetizadas a las salas de Juventud y Educación de Adultos, así como lo que piensan, y esperamos estar en este tipo de educación. Para ambos llevaron a cabo la investigación en una escuela Padre Pagliani en la ciudad de Yaguarón - RS con el fin de cumplir con estos individuos y así comprender las causas que apuntan a un regreso a la escuela después de la ausencia de muchos años de estudio. Con el fin de recopilar datos sobre el tema lanzado usando una entrevistas semiestructuradas y el círculo de conversación con los estudiantes. En cuanto a los fundamentos teóricos será tratado de recopilar estudios sobre la enseñanza y el aprendizaje, sus modelos pedagógicos, sus conceptos epistemológicos relacionados con la Alfabetización y Educación de Jóvenes y Adultos. La iniciativa no tiene grande, pero espero que ayude a minimizar la cuestión que impulsa mi trabajo y así traer alguna contribución a otros profesores y estudiantes sobre la necesidad de conocimiento acerca de las motivaciones de este trabajador público que supera años de prejuicio y la dependencia de otros en mundo alfabetizado en que vivimos

\footnotetext{
1 ("Licenciatura em Pedagogia; Universidade Federal do Pampa; Jaguarão, Rio Grande do Sul - Brasil; Cristiane.madeira@bol.com.br.”) Trabalho apresentado no III Encontro Humanístico Multidisciplinar e II Congresso Latino-Americano de Estudos Humanísticos Multidisciplinares, Jaguarão/RS, 2017.

2 ("Orientador Prof. Adjunto e Coordenador do Curso de Licenciatura em Pedagogia da Universidade Federal do Pampa (UNIPAMPA); Jaguarão, Rio Grande do Sul, Brasil; evertonoliveira@ unipampa.edu.com”). Trabalho apresentado no III Encontro Humanístico Multidisciplinar e II Congresso Latino-Americano de Estudos Humanísticos Multidisciplinares, Jaguarão/RS, Brasil, 2017.
} 
Palabras-clave: educación de los jóvenes; posibilidades; propuestas educativas;

\begin{abstract}
The present work aims to investigate the reasons for the return of the non literate subjects to the Youth and Adult Education rooms, as well as what they think, and expect to be in this modality of teaching. For that, I carried out a survey at the EMEF school - Municipal School of Primary Education (Municipal Public School) of the city of Jaguarão - RS in order to know these individuals and thus understand the causes that they point to back to school, after the absence of many years of study. As a way to gather data about the subject, I launched a semistructured interview script and a conversation with the students. As for the theoretical basis, I tried to gather studies about teaching and learning, their pedagogical models, their epistemological conceptions related to Literacy and Education of Young and Adults. The initiative does not have large dimensions, but I hope to help minimize the doubt that moves my work, and thus bring some contribution to other educators and learners about the need for knowledge, about the motivations of this working public, who wins years of prejudice and dependence on other people in the literate world we live in.
\end{abstract}

Keywords: youth education; possibilities; educational proposals;

\title{
1. Introdução
}

O propósito A inquietação para realização deste trabalho surge de dois momentos distintos, respectivamente de ação e formação: minha atuação no Programa Brasil Alfabetizado - PBA e a disciplina Os sujeitos e a prática pedagógica em EJA, componente curricular do curso de Licenciatura em Pedagogia da Universidade Federal do Pampa. Minha motivação primeiramente surgiu quando, no componente curricular, foi proposto um trabalho de pesquisa sobre a Educação de Jovens e Adultos no município de Jaguarão. Este pontapé inicial foi o primeiro contato com este público e me fez refletir sobre o processo de alfabetização para este público.

Quando recebi o convite para trabalhar no Programa Brasil Alfabetizado (PBA), que é um programa de alfabetização de Jovens e Adultos, foi um desafio muito grande, pois até o momento, minha experiência era somente com a Educação Infantil e os anos iniciais, limitada à prática do estágio supervisionado e os estágios contratados pela prefeitura. Ao realizar a pesquisa sobre a EJA me interessei pelo público alvo, admirei a força de vontade de vencer dessas pessoas, resolvi aceitar o desafio, e então me tornei uma alfabetizadora do (PBA). Este contato me possibilitou conhecer um pouco e aprender outras metodologias para trabalhar com estes sujeitos, conhecer o que cada um traz ao ingressar em uma sala de aula, seus medos, suas experiências, conhecimentos de mundo, a trajetória de vida, seus saberes adquiridos, todos estes aspectos. Assim, tentando levar estes aspectos em conta, foi me possibilitado trabalhar mais a realidade social e cultural concreta que cada um dos educandos vive. 
Nesses seis meses de ação pelo PBA, com três encontros semanais de aula, o aprendizado é constante, ensinamos, mas também aprendemos bastante, é um compartilhamento de saberes. Após o termino das aulas, alguns alunos que se interessarem a dar continuidade aos seus estudos, ingressarão em uma rede de ensino regular de EJA, e assim concluírem seus estudos.

Então direcionei essa pesquisa para uma EMEF - Escola Municipal de Ensino Fundamental (Escola Pública Municipal), Jaguarão/RS, que atende a modalidade da EJA à noite. Me propus ouvir os relatos dos alunos para assim descobrir quais são os motivos que levam esses alunos a retornarem à sala de aula? O que pensam, e esperam, ao estarem à sala de aula? Sendo assim, o objetivo é identificar e analisar os motivos sobre o retorno dos sujeitos não alfabetizados para as salas de Educação de Jovens e Adultos, bem como aquilo que pensam, e esperam ao estarem na nesta modalidade de ensino.

\section{FUNDAMENTAÇÃO TEÓRICA}

O compromisso do educador com e educando, conforme nos diz o documento CONFINTEA Vl (2010), sobre alfabetização de adultos:

A alfabetização é um pilar indispensável que permite que jovens e adultos participem de oportunidades de aprendizagem em todas as fases do continuum da aprendizagem. O direito à alfabetização é parte inerente do direito à educação. É um pré-requisito para o desenvolvimento do empoderamento pessoal, social, econômico e político. A alfabetização é um instrumento essencial de construção de capacidades nas pessoas para que possam enfrentar os desafios e as complexidades da vida, da cultura, da economia e da sociedade. (CONFINTEA, 2010, p. 07)

Nesse sentindo, FREIRE (1996) contribui a partir da seguinte reflexão:

Por isso mesmo pensar certo coloca ao professor ou, mais amplamente, à escola, o dever de não só respeitar os saberes com que os educandos, sobretudo os das classes populares, chegam a ela - saberes socialmente construídos na prática comunitária mas também, como há mais de trinta anos venho sugerindo, discutir com os alunos a razão de ser de alguns desses saberes em relação com o ensino dos conteúdos. Por que não aproveitar a experiência que têm os alunos de viver em áreas da cidade descuidadas pelo poder publico para discutir, por exemplo, a poluição dos riachos e dos córregos e os baixos níveis de bem-estar das populações, os lixões e os riscos que oferecem à saúde das gentes. Por que não há lixões no coração dos bairros ricos e mesmo puramente remediados dos centros urbanos? (...) Por que não discutir com os alunos a realidade concreta a que se deva associar a disciplina cujo conteúdo se ensina, a realidade agressiva em que a violência é a constante e a convivência das pessoas e muito maior com a morte do que com a vida? Por que não estabelecer uma necessária "intimidade" entre os saberes curriculares fundamentais aos alunos e a experiência social que eles tem como indivíduos? (FREIRE, 1996, p. 33-34) 
Cabe nessa fundamentação teórica, uma breve retrospectiva da Educação de Jovens e Adultos no Brasil.

O Brasil passou por diversas manifestações ao longo dos anos. Em relação à isto, a Constituição Imperial de 1824, determinava que todos os cidadãos tinham o direito de aprender no ensino primário de forma gratuita, porém os indígenas, escravos e caboclos não se incluíam no "todos", pois estes não eram considerados cidadãos. (OLIVEIRA, et. al. 2014)

Vários movimentos surgiram ao longo das décadas, mas em 1942, é que a educação de adultos se instaura como política educacional e se detecta um alto índice de analfabetismo, tentando reverter à situação, o governo cria um fundo destinado à alfabetização dos adultos, surge o Fundo Nacional de Ensino Primário, e surgem, outras iniciativas locais e estaduais.

No Rio de Janeiro acontece o $1^{\circ}$ congresso Nacional de Educação de Adultos, criado pelo professor Anísio Teixeira, acontecimento ocorrido na década de 1947.

Quase na década de 60 houve um "Congresso de Educação de Adultos", onde participaram vários estados, na ocasião destacaram-se as experiências de Paulo Freire e após foi criada a Campanha Nacional de Erradicação do Analfabetismo (CNEA). Ainda na década de 60 foi criado o Instituto Nacional de Estudos e Pesquisas Educacionais Anísio Teixeira (INEP), e também o Plano Nacional de Alfabetização de Adultos (PNAA), dirigido por Paulo Freire, Cruzada Ação Básica Cristã (ABC) e o Movimento Brasileiro de Alfabetização (MOBRAL).

Com aprovação da Lei no . 5.692/71 é então regulamentado o Ensino Supletivo (esse grau de ensino visa a contemplar os jovens e adultos); foram mais conquistas adquiridas. Porém na década de 90, é criado o Programa Nacional de Alfabetização e Cidadania (PNAC), e quase no mesmo período a Lei de Diretrizes e Bases da Educação Nacional, que substitui a denominação Ensino Supletivo, pela Educação de Jovens e Adultos como modalidade de ensino.

A Lei de Diretrizes e Bases da Educação Nacional (n9. 394/96), prevê a igualdade para todos e acesso e permanência na escola, liberdade de aprender, ensinar, pesquisar e divulgar a cultura, o pensamento, a arte e o saber, assim como a educação - dever da família e do estado - inspirada nos princípios de liberdade e nos ideais de solidariedade humana, tem por finalidade o pleno desenvolvimento do educando, seu preparo para o exercício da cidadania e sua qualificação para o trabalho.

No título V, capitulo II, Seção V, encontramos dois artigos relacionados, especificamente, à Educação de Jovens e Adultos: 
Artigo 37 - A Educação de Jovens e Adultos será destinada àqueles que não tiveram acesso ou continuidade de estudos no ensino fundamental e médio na idade própria. $\S 1^{\circ}$. Os sistemas de ensino assegurarão gratuitamente aos jovens e aos adultos, que não puderam efetuar os estudos na idade regular, oportunidades educacionais apropriadas, consideradas as características do alunado, seus interesses, condições de vida e trabalho, mediante cursos e exames.

$\S 2^{\circ}$. O Poder Público viabilizará e estimulará o acesso e a permanência do trabalhador na escola, mediante ações integradas e complementares entre si.

Artigo 38 - Os sistemas de ensino manterão cursos e exames supletivos, que compreenderão a base nacional comum do currículo, habilitando ao prosseguimento de estudos em caráter regular.

$\S 1^{\circ}$. Os exames a que se refere este artigo realizar-se-ão:

I. no nível de conclusão do ensino médio, para maiores de quinze anos;

II. no nível de conclusão para maiores de dezoito anos.

$\S 2^{\circ}$. Os conhecimentos e habilidades adquiridos pelos educando por meios informais serão aferidos e reconhecidos mediante exames.

A educação é um direito de todos, em qualquer faixa etária em que o cidadão se encontre, a educação passa a ser dever do Estado, com ensino fundamental obrigatório e gratuito, assegurada, inclusive sua oferta gratuita para todos que não tiverem acesso a educação na idade própria. (BRASIL, 1996)

A Educação de Jovens e Adultos (EJA) é a modalidade de ensino nas etapas dos ensinos fundamental e médio da rede escolar pública brasileira que recebe os jovens e adultos que não completaram os anos da Educação Básica em idade apropriada por qualquer motivo.

Com a Resolução CNE/CEB N N $^{\circ}$, de 05/07/2000, os exames supletivos, passaram então, a certificar as etapas do ensino fundamental e do ensino médio da Educação de Jovens e Adultos, sendo um momento de muita conquista para esses jovens.

Segundo as pesquisas do IBGE (2014) nas escolas de EJA, as inscrições geralmente são inúmeras, porém conseguir a permanência das pessoas inscritas na conclusão, é um grande desafio para a escola, e para o educador, sendo que o mesmo, desenvolve um papel importante em estimular, incentivar, buscar seu aluno, para este dar continuidade aos seus estudos, sabemos que a prática educativa é acima de tudo um desafio, para o educador que passa grande parte do seu tempo questionando-se, buscando dar o melhor a seus educandos, através de pesquisas de metodologias que sejam adequadas a faixa etária, pois segundo Paulo Freire:

Não há ensino sem pesquisa e pesquisa sem ensino. Esses que-fazeres se encontram um no corpo do outro. Enquanto ensino continuo buscando, reprocurando. Ensino porque busco, porque indaguei, porque indago e me indago. Pesquiso para constatar, constatando, intervenho, intervindo educo e me educo. Pesquiso para conhecer o que ainda não conheço e comunicar ou anunciar a novidade. (FREIRE, 1996, p. 14) 
O Ministério da Educação (MEC) desenvolve com municípios e estados, o Programa Brasil Alfabetizado (PBA), que é um projeto do Governo Federal implantado desde 2003, voltado para a alfabetização de Jovens e Adultos, sem limite de idade, sendo uma oportunidade que a pessoa tem de se alfabetizar e ingressar numa escola e dar seguimento aos seus estudos. Podem participar jovens com 15 anos ou mais, adultos e idosos.

Os programas de incentivo estão dando certo, segundo a pesquisa Nacional por Amostra de Domicílio (Pnad) de 2013, pelo Instituto Brasileiro de Geografia e Estatística (IBGE). Tal pesquisa mostra que o analfabetismo recuou em todas as regiões do Brasil e em todas as faixas etárias. A taxa de analfabetismo caiu de 8,7\% em 2012 para 8,3\% em 2013, considerando a população com 15 anos ou mais. Se a comparação for estendida para os últimos 10 anos, verifica-se avanço ainda mais significativo: a taxa diminuiu de $11,5 \%$ em 2004 para $8,3 \%$ em 2013.

Com tantas mudanças ocorridas no cenário escolar, percebe-se que o ensino mudou, e que precisamos de um profissional devidamente qualificado, para atender e conhecer a realidade destes educandos. De acordo com Jaqueline Moll (2004):

Fazer-se professor de adultos implica disposição para aproximações que permanentemente transitam entre saberes constituídos e legitimados no campo das ciências, das culturas e das artes e saberes vivenciais que podem ser legitimados no reencontro com o espaço escolar. No equilíbrio entre os dois a escola possível para adultos. (MOLL, 2004, p.17)

Ao mesmo tempo esses adultos das classes de EJA resistem à metodologia de ensino, "por possuírem tantas experiências, também possuem uma consciência formada, regras, normas pessoais, ideias, concepções, tradições, e tudo aquilo que alguém pode carregar" (MARTINEZ, 2015). O aluno de EJA é um sujeito que não teve possibilidade de estudar idade certa, mas que merece respeito como sujeito pensante crítico e atuante na sociedade. $\mathrm{O}$ professor é responsável por esse aluno que chega desacreditado as salas de aula porque carrega com ele os medos e as frustações causadas por aqueles que deveriam apoiar seu desenvolvimento cognitivo. Steyer (2011) faz uma reflexão pertinente sobre a alfabetização dos adultos e das crianças:

Se a criança está "conhecendo o mundo" (FREIRE, 1993), o adulto das classes de EJA já vive nele há décadas. Não é possível desconsiderar toda esta "ampla e longa experiência", que a criança não tem, e propor as mesmas atividades que são propostas para as crianças. Não é possível apresentar atividades com "bonequinhos" ou "bichinhos", ou textos infantilizados, para adultos que vivenciam diariamente as agruras da sua sobrevivência e da sua família. Não é possível que os pais (ou avós), 
no turno da noite, façam as mesmas atividades que seus filhos (ou netos) fazem durante o dia. (STEYER, 2011, p. 58)

A alfabetização neste sentido precisa ser compreendida além da "decodificação".

Soares (2003) define alfabetização como:

O processo específico e indispensável de apropriação do sistema de escrita, a conquista dos princípios alfabético e ortográfico que possibilitem ao aluno ler e escrever com autonomia. Noutras palavras, alfabetização diz respeito à compreensão e ao domínio do chamado código escrito, que se organiza em torno de relações entre o que se escreve (grafemas) e o que se fala (fonemas). (SOARES, 2003, p. 14)

O mesmo conceito é compartilhado por Schwartz (2010) que compreende que: "No sentido etimológico, alfabetizar significa "levar a aquisição do alfabeto", o que deixa o termo reduzido a uma estratégia mecânica, articulada com a habilidade de codificar e decodificar grafemas e fonemas" (SCHWARTZ, 2010, p.24). Já para Ferreiro (2001) alfabetização é mais do que a transmissão de códigos alfabéticos e cita que:

\footnotetext{
A invenção da escrita foi um processo histórico de construção de um sistema de representação, não um processo de codificação. Uma vez construído poder-se ia pensar que o sistema de representação é aprendido pelos novos usuários, como um sistema de codificação. Entretanto, não é assim, no caso dos dois sistemas envolvidos no início da escolarização ( o sistema de representação dos números e o sistema de representação da linguagem) as dificuldades que as crianças enfrentam são dificuldade conceituais semelhantes as da construção do sistema e por isso podese dizer em ambos os casos que a criança reinventa esses sistemas. Bem entendido: não se trata de que as crianças reinventem as letras nem os números, mas que, para poderem se servir desses elementos como elementos de um sistema, deve compreender seu processo de construção e suas regras de produção, o que coloca o problema epistemológico fundamental: Qual é a natureza da relação entre o real e a sua representação? (FERREIRO, 2001, p.12)
}

Deslocando a discussão ao ensino e não somente à alfabetização, destaco que Fleuri (1987) entende que as decisões das práticas e planejamentos devem ser discutidas com o grupo a qual vai se trabalhar, para que haja uma reflexão de decisões, sob os acordos das metodologias, o processo avaliativo deve ser debatido também entre professor e aluno. Quando o professor é o único ser pensante e decide tudo sozinho ele será apenas um comunicador, formulou todo processo sem a devida participação dos educandos, deixando de ser um espaço democrático e tornando-o autoritário.

O autor aborda três concepções que são: a Autoritária, a Liberal, e a Libertadora. A concepção autoritária é aquela que o professor e o centro do saber e o aluno só reproduz o que escuta. Já na concepção liberal, o aluno pode atuar como um ser pensante para resolver um problema. Na concepção libertadora, as decisões dos problemas são pensadas e debatidas em 
grupo até que se chegue a uma solução. De encontro a esse pensamento entende-se que o professor deverá conhecer seu aluno dar oportunidades para seu desenvolvimento intelectual e social, tornando-o participativo nas tomadas de decisões, e não aliená-lo perante a sociedade, queremos pessoas que sejam capazes de pensar e atuar em sociedade, principalmente no que confere à participação democrática.

\title{
3 METODOLOGIA
}

Foi preciso refletir sobre quais metodologias comporiam este trabalho, de que forma construir esta pesquisa. De acordo com Gil (1994, p.42) a pesquisa tem por objetivo fundamental "descobrir respostas para problemas, mediante o emprego de procedimentos científicos".

O trabalho desenvolvido está orientado metodologicamente como uma pesquisa qualitativa, podendo ser conceituado como um estudo de caso. Conforme Minayo (2007, p.10):

\begin{abstract}
A pesquisa qualitativa responde a questões muito particulares. Ela se ocupa, nas Ciências Sociais, com um nível de realidade que não pode ou não deveria ser quantificado. Ou seja, ela trabalha com o universo dos significados, dos motivos, das aspirações, das crenças, dos valores e das atitudes. Esse conjunto de fenômenos humanos é entendido aqui como parte da realidade social, pois o ser humano se distingue não só por agir, mas por pensar sobre o que faz e por interpretar suas ações dentro e a partir da realidade vivida e partilhada com seus semelhantes.
\end{abstract}

O estudo de caso é utilizado em muitas circunstâncias e situações e contribuem com o "conhecimento dos fenômenos individuais, organizacionais, sociais, políticos e de grupo, além de outros fenômenos relacionados" (YIN, 2005, p. 20). Mas para Triviños (1987, p.113) afirma o estudo de caso ser "uma categoria de pesquisa cujo objeto é uma unidade que se analisa profundamente".

Utilizei entrevistas abertas com estudantes com mais de quinze anos, buscando caracterizá-los, compreender como os entrevistados deram continuidade aos seus estudos, e o que esperam ao entrar em uma sala de aula.

O uso de entrevista é reconhecido por Lüdke e André (1986, p. 34), pois “ela permite a captação imediata e corrente da informação desejada, (...) ganha vida ao se iniciar o diálogo entre o entrevistador e o entrevistado".

Nesta pesquisa, o método utilizado para obtenção de dados primários foi a observação participante. A observação participante ou observação ativa, conforme Gil (1994) consiste no tipo de observação na qual existe a real participação do observador na vida da comunidade, do 
grupo ou de uma situação determinada. O observador assume o papel de um membro do grupo.

Elaborei a presente pesquisa com os alunos da EJA do ensino fundamental de uma escola municipal de Jaguarão - RS pensando nos motivos que levaram esses jovens e adultos a retornarem aos estudos. E sobre o que pensam, e esperam esses sujeitos ao estarem em sala de aula?

$\mathrm{Na}$ investigação foram ouvidos cinco alunos que aceitaram responder minhas perguntas. Esses alunos serão identificados apenas por números para manter o anonimato e sua privacidade que responderam as seguintes perguntas:

1) Quais os motivos levaram esses alunos voltarem a estudar?

2) O que pensam, esperam esses alunos ao entrarem na sala de aula em EJA?

A pesquisa qualitativa, com definição de estudo de caso foi realizada por meio de das perguntas acima relacionadas, com cinco alunos que frequentam a EJA, duas mulheres e três homens.

\section{ANÁLISE E DISCUSSÃO DOS DADOS}

Elaborei a presente pesquisa com os alunos da EJA, na Escola Municipal de Ensino Fundamental (Escola Pública Municipal) Jaguarão - RS, pensando nos motivos que levaram esses jovens e adultos a retornarem os estudos. É sobre o que pensam, e esperam esses sujeitos ao estarem em sala de aula? $\mathrm{Na}$ investigação foram ouvidos cinco alunos, que aceitaram responder minha pergunta.

Para preservar a identidade dos alunos, identificarei por sujeito S1, S2, S3, S4 S5. A seguir, uma breve descrição de cada um dos educandos pesquisados.

$\mathrm{O}$ aluno S1 tem 58 anos, trabalha como pedreiro. Quando criança aponta que já tinha estudado, tinha uns 10 anos de idade, quando parou os pais não influenciaram ao estudo e sim a trabalhar, agora faz cerca de três anos que voltou a estudar.

O aluno S2 tem 52 anos, trabalha como pintor desde os 16 anos. Relatou que estudou quando era pequeno na zona rural até a segunda série, voltou a estudar faz cerca de 3 a 4 anos.

A aluna S3, parou de estudar porque trabalhava, agora faz cerca de dois anos que retornou aos estudos.

A aluna S4 39 anos é doméstica, nunca tinha estudado. Ela relata que: 
Desde pequena já tinha de trabalhar para ajudar a mãe. Mas agora ela tenta recuperar o tempo perdido. Sente muito vergonha de não saber ler.

A aluna voltou a estudar esse ano, porque já criou seus filhos, é sonho que se realiza depois de anos sem estudar.

Aluno S5 é pedreiro, e faz dois anos que voltou a estudar.

Descreverei os alunos por sujeito, sendo S1, S2, S3, S4 e S5, sob a primeira pergunta:

1) Quais os motivos que esses alunos retornam a estudar?

$\mathrm{O}$ aluno $\mathrm{S} 1$, diz que os motivos que o fizeram retornar aos estudos foi para conseguir ler e escrever para conseguir um emprego, melhor remunerado;

Já o aluno S2, afirma que seu objetivo é aprender a ler e escrever, para saber se locomover na cidade, saber ler uma placa, uma receita médica, uma notícia em um jornal, o nome de uma rua, etc.; e em suas palavras: "Uma pessoa sem saber ler é uma pessoa sem rumo, porque não sabe nada".

A aluna S3, informa que, quer saber ler a conta da luz, água, viajar sozinho, e conseguir ler a bíblia.

A aluna S4 quer aprender a ler para ter acesso a informações tecnológicas; internet e celular.

O aluno S5, voltou aos estudos porque precisa aprender a matemática pra não "fazer as coisas erradas" no serviço.

Após coletar e analisar os dados fica claro entender que os motivos que os levaram de volta à escola foram distintos, porém, um foi unânime todos declararam ser um "sonho" aprender a ler e escrever.

Em minha segunda pergunta, a qual descrevo abaixo, obtive as seguintes respostas.

2) O que você pensa ou espera ao estar na sala de aula?

O aluno S1, diz ser um espaço de aprendizado, e mais uma chance que a vida dá para as pessoas aprenderem, esperando ele conseguir, ir bem longe a seus estudos.

Já o aluno S2, diz que é voltar no tempo, pois: "a gente não aprendeu quando novo, agora tem outra chance, depois de "burro velho" e não dá para desperdiçar".

A aluna S3, relata que, aprende coisas que nem sabia que existia, "o estudo é à base de tudo" e diz que os professores são bons, tem paciência. É tudo muito bom e ela deseja seguir e terminar seus estudos.

A aluna S4, diz que a escola é boa, que está aprendendo a ler, e é um sonho que ele realiza depois de anos sem estudar, espera aprender mais e mais. 
O aluno S5, conclui que a EJA é uma oportunidade para a gente que trabalha o dia todo, diz que a professora é boa, que ela incentiva eles, e espera ter bastante saúde para seguir seus estudos.

A partir das falas, ficam à mostra expressões peculiares como "estudo é à base de tudo". "uma pessoa sem saber ler é uma pessoa sem rumo", "capacidade para mudar de cargo eu tenho o que não tenho é a instrução necessária”.

Pelos motivos expostos anteriormente e os depoimentos, nota-se que a volta à escola, serve para satisfação pessoal através de empregos diferentes daqueles que eles executam atualmente, e para sentirem-se cidadãos capazes de executar tarefas que parecem simples para quem tem estudo, mas para estes alunos é uma conquista diária cada vez que consegue ler o nome de uma rua, saber que remédio tomar naquele horário ou ler um jornal. Vieira Pinto nos ajuda a compreender a necessidade de educação para estes adultos. Pois segundo ele:

É uma tese errônea e cruel e admitir que se deve condenar os adultos á condição perpetua de letrados e concentrar os recursos da sociedade na alfabetização da criança, mais barata e de maior rendimento futuro, deixando de lado o vergonhoso desprezo moral pela dignidade do homem que esta tese encerra, ela é: sociologicamente falsa, pois o adultos rende muito mais depois de alfabetizado; (VIEIRA PINTO, 2000, p. 81).

Todos concordam, quando o que esperam ao entrar em uma sala de aula é aprender a ler e a escrever, e o segundo lugar para conseguir um emprego melhor. Neste sentido Schwartz, nos diz que:

A aprendizagem da leitura e da escrita, ao habilitar o aprendiz a ler, a produzir, a explicar e a compreender qualquer tipo de texto de que necessitar, ou que desejar, amplia as possibilidades de inclusão do sujeito e pode contribuir ainda para diminuir a desigualdade social. (SCHWARTZ, 2010, p. 54)

Segundo os entrevistados todos estão gostando de aprender, os professores são bons, acham os conteúdos desenvolvidos claros, estão aprendendo e atendem as suas expectativas e anseios. Segundo caderno 1 da EJA:

A visão de mundo de uma pessoa que retorna aos estudos depois de adulta, após um tempo afastado da escola, ou mesmo daquela que inicia sua trajetória escolar nessa fase da vida, é bastante peculiar. Protagonistas de histórias reais e ricos em experiências vividas, os alunos jovens e adultos configuram tipos humanos diversos. São homens e mulheres que chegam à escola com crenças e valores já constituídos. Nas cidades, as escolas para jovens e adultos recebem alunos e alunas com traços de vida, origens, idades, vivências profissionais, históricos escolares, ritmos de aprendizagem e estruturas de pensamento completamente variados. A cada realidade corresponde um tipo de aluno e não poderia ser de outra forma, são 
pessoas que vivem no mundo adulto do trabalho, com responsabilidades sociais e familiares, com valores éticos e morais formados a partir da experiência, do ambiente e da realidade cultural em que estão inseridos. (BRASIL, 2006, p.04)

Esses alunos da EJA estão buscando incluir-se efetivamente na sociedade, melhorando sua capacidade de executar serviços diários sem a humilhação de depender de outros. Nessa entrevista pude notar que os adultos são os que mais se interessam em aprender, são mais assíduos e comemoram cada aprendizado como uma grande conquista e os alunos se ajudam uns aos outros quando conseguem entender os conteúdos. Nesse sentido ressalto o texto de Cagliari (1999) sobre ensinar e aprender em que o autor descreve:

Ensinar é um ato coletivo: pode-se ensinar a um grande número de pessoas presentes numa sala ou numa conferência, etc. Quem ensina procura transmitir informações que julga relevantes, organizadas do modo que lhes parece mais razoável, para que seus ouvintes aprendam algo que deseja transmitir. Aprender é um ato individual: cada um aprende segundo seu próprio metabolismo intelectual. A aprendizagem não se processa paralelamente ao ensino. O que é importante para quem ensina, pode não parecer tão importante para quem aprende. A ordem da aprendizagem é criada pelo indivíduo, de acordo com sua história de vida e, raramente, acompanha passo a passo a ordem do ensino. (CAGLIARI, 1998, p. 36-37).

\section{CONSIDERAÇÕES FINAIS}

Considero após esta imersão na realidade sobre o tema, que o principal empecilho para a escolarização dos adultos pobres trabalhadores, ainda é, o sustento familiar para que as pessoas possam voltar aos estudos, pois constituem famílias ainda jovens. Isso se torna mais evidente com as mulheres, por serem mães cedo e por vezes sozinhas, se veem obrigadas a manter a casa e os filhos, trabalhando naquilo que lhe oferecer o sustento, com isso o estudo fica renegado a terceiro plano e somente voltam a pensar sobre esse assunto quando os filhos estão criados e elas muitas vezes já aposentadas. Os adolescentes também em alguns casos são obrigados a trabalhar para auxiliar nas despesas de casa, deixando a escola para mais tarde, contribuindo dessa forma para o índice de analfabetismo no Brasil.

A Educação de Jovens e Adultos é uma modalidade diferenciada de ensino, ou pelo menos deveria ser, pois, não se pode infantilizar o adulto utilizando o mesmo método usado para alfabetizar as crianças. Se por um lado tanto o adulto quanto a criança não são alfabetizados, por outro lado o adulto traz em si uma bagagem de vida, bem maior que a da criança que está apenas iniciando sua vida. Dessa forma é necessário que os professores tenham em mente, uma proposta diferenciada para esses alunos que vem para as aulas portando saberes práticos que não se encontram nas teorias, mas que são lições diárias para aqueles que convivem com eles em seu cotidiano. 
O professor ao analisar cada percurso de seus alunos, deverá coletar dados para ver quais são os conhecimentos trazidos pelos seus alunos ao longo de suas experiências, suas bagagens de conhecimento. Nesse sentido, os docentes em exercício das classes de EJA, podem contribuir na aprendizagem e crescimento dos educandos e para tanto, uso de estratégias diversas, desde conversas informais até o uso de mídias atuais além do material didático apropriado para alcançar seus objetivos se torna fundamental.

Assim acredito que meu objetivo principal neste trabalho gerou novas inquietações e preocupações sobre a necessidade de aprofundarmos temas relacionados à EJA além de entender um pouco os reais dos motivos que levaram os jovens e adultos a retornar aos estudos, e o que pensam e esperam em sala de aula. Entendo, depois de ouvi-los, que são sujeitos buscando seu lugar na sociedade atual. Essa sociedade que é cada vez mais letrada, com códigos e expressões em transformações diárias. Ao estarem fora do ambiente escolar esses sujeitos são excluídos do convívio em sociedade e sentem-se discriminados pelo turbilhão de informações que são obrigados a vivenciar em seu cotidiano. São pessoas que buscam uma oportunidade de crescimento, e procuram as salas de aula da EJA, pois querem ser pessoas capazes de aprender, mesmo que não aprenderam por falta de oportunidade na vida.

\section{Referências}

BRASIL. Lei de Diretrizes e Bases da Educação Nacional. Lei n ${ }^{\circ} 9.394$ de 20 de dezembro de 1996... - Brasília : Senado Federal, Subsecretaria de Edições técnicas, 2002.

BRASIL, Ministério da Educação. EJA Caderno 1. Disponível em: http://portal.mec.gov.br/secad/arquivos/pdf/eja_caderno1.pdf Acesso em: 15 dezembro 2015 (Modelo para Sites).

BRASIL. Ministério da Educação e Cultura. Departamento de Educação de Jovens e Adultos. Trabalhando com Educação de Jovens e Adultos: Alunos e Alunas da EJA. Brasília, 2006.

CAGLIARI, Luiz Carlos. Alfabetizando sem o bá-bé-bi-bó-bú. Pensamento e Ação no Magistério. São Paulo: Scipione, 1998. (Obra completa)

FERREIRO, Emilia. Reflexão sobre alfabetização/ Emilia Ferreiro: Tradução Horácio Gonzáles (et. al.), 24 ed. atualizada - São Paulo: Cortez, 2001. - (coleção questões da nossa época; v. 14). .(Obra completa)

FREIRE, Paulo. Pedagogia da autonomia: saberes necessários à prática educativa. São Paulo: Paz e Terra, 1996 (Coleção Leitura) 
FLEURI, Reinaldo Matias. Educar para quê? Contra o autoritarismo da relação na prática pedagógica. 2.ed. Uberlândia, Ed. UFU, 1987. .(Obra completa).

GIL, Antônio Carlos. Administração de recursos humanos: um enfoque profissional. Atlas.

São Paulo, 1994. .(Obra completa).

IBGE__http://portal.inep.gov.br/visualizar/-/asset_publisher/6AhJ/content/pesquisa-apontaqueda-do-analfabetismo. Acesso em: 26 novembro 2017. (Modelo para Sites).

IRELAND, T. UNESCO - CONFERÊNCIA INTERNACIONAL DE EDUCAÇÃO DE ADULTOS - CONFINTEA. Contextualização dos CONFINTEA's anteriores à CONFINTEA VI. Disponível em: http://www.forumeja.org.br . Acesso em 10 dezembro de 2017.

LÜDKE, Menga; ANDRÉ, Marli. Pesquisa em educação: abordagens qualitativas. São Paulo: EPU, 1986. (Temas básicos de educação e ensino). (Capitulo de livro)

MARTINEZ, Lucas da S. Relatório de estágio. 2015a, 171 f. (Licenciatura em Pedagogia) Universidade Federal do Pampa, Jaguarão.

MINAYO, Maria. C.S. (org.) Pesquisa Social: Teoria, método e criatividade. 26 ed.. Petrópolis, RJ: Vozes, 2007.

MOLL, Jaqueline. Educação de Jovens e Adultos / Jaqueline Moll, (org.) Sita Maria Lopes Sant'Anna ... [et. al.]- Porto Alegre: mediação, 2004. 144 p. - (Série Projetos e Práticas Pedagógicas).

OLIVEIRA, Everton - Olhares múltiplos e contemporâneos da educação de jovens e adultos - (org.) Sita Mara Lopes Sant' Anna e Leandro Forell.- Porto Alegre/RS: UERGS, 2014. PBA._http://portal.mec.gov.br/par/194-secretarias-112877938/secad-educacao-continuada223369541/17457-programa-brasil-alfabetizado-novo.

PESQUISA NACIONAL POR AMOSTRA DE DOMICÍLIO (Pnad) de 2013, http://www.ipm.org.br/ptbr/programas/inaf/relatoriosinafbrasil/Paginas/default.aspx.

RIBEIRO, Vera M. Masagão et al. Educação para jovens e adultos: ensino fundamental: proposta curricular $-1^{\circ}$ segmento - São Paulo: Ação Educativa; Brasília: MEC, 2001. (Obra completa).

SCHWARTZ, Suzana. Alfabetização de jovens e adultos: teoria e prática. Petropólis: Vozes, 2010. (Obra completa).

SOARES, Magda. As muitas facetas da alfabetização. In: Alfabetização e letramento. São Paulo: Contextos, 2003. SOARES, Magda. Alfabetização e letramento, $2^{\circ}$ ed. São Paulo: Contexto, 2004. (Obra completa).

SOARES, Magda. Letramento: um tema em três gêneros. 3 ed. Belo Horizonte: Autêntica, 2009. (Obra completa). 
STEYER, V. E. É possível replicar os conhecimentos construídos sobre a alfabetização de crianças para a alfabetização nas classes de EJA? In: SCHEIBEL, M. F.; LEHENBAUER, S. (org.) EJA: pertinências e perspectivas. 1. ed. - Curitiba, PR: CRV, 2011. (Obra completa).

TRIVIÑOS, A, N, S. Introdução à pesquisa em ciências sociais. São Paulo: Atlas, 1987. (Obra completa).

VIEIRA, PINTO, A. Sete lições sobre a educação de adultos. 11. Ed. São Paulo, SP: Cortez, 2000. (Obra completa).

YIN, R. K. Estudo de caso Planejamento e métodos. 3. Ed. Porto Alegre: Bookman, 2005. (Obra completa). 